\title{
PENGETAHUAN ORANG TUA TENTANG JAJANAN SEHAT DENGAN KEJADIAN DIARE PADA USIA SEKOLAH
}

\section{Parents Knowledge About Healthy Services with Diarrhea Events in School}

\author{
Rohaeti $^{1}$, Rahmawati ${ }^{1}$, Dewi Nur Puspita Sari ${ }^{1}$, Ii Padilah ${ }^{2}$
}

1. Dosen S1 Keperawatan, STIKes Yatsi Tangerang

2. Alumnus S1 Keperawatan STIKes Yatsi Tangerang

\section{Riwayat artikel \\ Diajukan:}

29 Februari 2020

Diterima:

10 September 2020

\section{Penulis Korespondensi: \\ - Dewi Nur Puspita Sari \\ - Dosen S1 Keperawatan, STIKes Yatsi \\ Tangerang \\ dewinurpuspitasari16@g $\underline{\text { mail.com }}$}

\section{Kata Kunci:}

peran oarangtua, kejadian diare

\begin{abstract}
Abstrak
Pendahuluan: Banyaknya jenis jajanan yang ada dilingkungan membuat anak sekolah dengan bebas dapat mengkonsumsi jajanan tersebut, menurut badan pengawas obat dan makanan, jajanan dilingkungan sekolah banyak yang mengandung bahan berbahaya bagi tubuh dan dapat menyebabkan masalah kesehatan seperti diare. Berdasarkan hasil studi pendahuluan dengan wawancara dan observasi terhadap orang tua di Kampung Cilongok RT 004 dan 005, Kecamatan Pakuhaji Kabupaten Tangerang sebanyak 20 orang tua dan terdapat pengetahuan baik sebanyak 10 responden, pengetahuan cukup sebanyak 7 responden, dan pengetahuan kurang sebanyak 3 responden. Dari 20 responden yang mengalami diare sebanyak 10 anak usia sekolah. Tujuan: Tujuan dari penelitian ini adalah untuk mengetahui pengetahuan orang tua tentang jajanan sehat dengan kejadian diare pada anak usia sekolah di Kampung Cilongok RT 004 dan 005 Kecamatan Pakuhaji Kabupaten Tangerang Tahun 2019. Metode: Jenis penelian ini adalah kuantitatif dengan deskriptif korelatif sempel yang digunakan dalam penelitian ini adalah sebanyak 92 responden. Teknik analisis yang digunakan adalah univariat untuk mempeoleh karakteristik dari masing-masing variabel demografis dan analisis bivariat digunakan untuk mengetahui hubungan antar variabel. Hasil: Data dianalisis dengan menggunakan uji ci square dan didapatkan statistik nilai $P$ value sebesar 0,019 . Hal ini menunjukkan nilai $P$ value pada pengetahuan orang tua tentang jajanan sehat dengan kejadian diare bahwa $<0,05$ terdapat peran orang tua tentang jajanan sehat dengan kejadian diare. Saran: Hendaknya orang tua lebih aktif dalam mencari informasi atau wawasan baru untuk menghindari kejadian diare pada anak usia sekolah.
\end{abstract}

\section{Abstract}

Background: The many types of snacks available in the environment make school children can freely consume these snacks, according to the drug and food regulatory agency, many school snacks that contain substances harmful to the body and can cause health problems such as diarrhea. Based on the results of a preliminary study with interviews and observations of parents in Kampong Cilongok RT 004 and 005, Pakuhaji District Tangerang Regency as many as 20 parents and there is good knowledge as much as 10 respondents, enough knowledge of 7 respondents, and less knowledge of 3 respondents. Of the 20 respondents who experienced diarrhea as many as 10 school-age children. Objective: To determine the knowledge of parents about healthy snacks with the incidence of diarrhea in school-age children in Kampong Cilongok RT 004 and 005 Pakuhaji District Tangerang District in 2019. Methods: This type of research is quantitative with a correlative descriptive descriptive used in this research is 92 respondents. The analysis technique used is univariate to obtain the characteristics of each demographic variable and bivariate analysis is used to determine the relationship between variables. Results: Data were analyzed using the ci square test and the statistical value of the P value was 0.019. This shows the value of P value on the knowledge of parents about healthy snacks with the occurrence of diarrhea that $<0.05$ there is a role of parents about healthy snacks with the incidence of diarrhea. Suggestion: Parents should be more active in finding information or new insights to avoid the occurrence of diarrhea in school-age children 


\section{PENDAHULUAN}

Penyakit diare masih merupakan masalah global dengan tingkat kesakitan dan kematian yang tinggi di berbagai negara terutama di negara berkembang. Menurut World Health Organization (WHO,2011), diare merupakan penyebab nomor satu kematian pada balita di seluruh dunia, dimana setiap tahun diare terjadi sekitar 1,5 juta yang menyebabkan balita hingga meninggal dunia. Setiap tahun diperkirakan 2,5 milyar kejadian diare pada anak balita, dan hampir tidak ada perubahan dalam dua dekade terakhir. Anak-anak merupakan kelompok usia rentan terhadap diare, insiden diare tertinggi pada kelompok anak usia dibawah dua tahun, dan menurun dengan bertambahnya usia anak (Dewi, Marini dan Sagita, 2018).

Berdasarkan survei morbiditas yang dilakukan oleh subdit diare, Departemen Kesehatan Republik Indonesia tahun 2011, proporsi terbesar penderita diare pada balita adalah kelompok umur 6-11 bulan sebesar $21,65 \%$, kelompok umur 12-17 bulan sebesar $14,43 \%$, kelompok umur 24-29 bulan sebesar $12,37 \%$. Diare merupakan keadaan ketika seseorang mengalami peradangan pada kolon sehingga meyebabkan tinjanya encer, dapat bercampur darah dan lendir kadang disertai muntah-muntah, sehingga diare dapat menyebabkan cairan tubuh terkuras keluar melalui tinja. Bila penderita diare banyak sekali kehilangan cairan tubuh makan hal ini dapat menyebabkan kematian terutam pada bayi dan anak-anak (Soedjatmiko, 2008 dalam Dewi, Marini dan Sagita, 2018).

Data Kementrian Kesehatan Indonesia (2016) menyatakan, jumlah kasus diare yang ditangani instansi kesehatan di Indonesia menurun tiap tahunnya. Pada tahun 2016 penderita diare di Indonesia yang ditangani sebanyak $46,4 \%$ dari jumlah penderita diare keseluruhan yang tercatat berjumlah 6.897.463 orang. Pada tahun 2015, jumlah kasus yang ditangani 4.017.861 orang, sedangkan pada tahun 2014 jumlah penangan kasus diare oleh instasi kesehatan adalah 8.490976 orang.

Data Profil Kesehatan Kabupaten Tangerang frekuensi penderita diare semua umur pada tahun 2014 yaitu 51.337 penderita diare, pada tahun 2015 terjadi peningkatan yaitu 77.254 penderita diare dan menurun pada tahun 2016 yaitu 53.712 penderita diare.

Diare merupakan suatu penyakit yang ditandai dengan buang air besar dengan frekuensi lebih dari 3 kali dalam sehari dan berkonsistensi encer, penyakit ini sering dijumpai pada anakanak (Ariani, 2016 dalam Gultom, Franly dan Hendro, 2018). Diare sering terjadi pada anakanak dikarenakan anak-anak banyak yang membeli makanan jajanan yang sembarangan, seperti anak usia sekolah dasar lebih sering jajan berupa es atau kue-kue dan cenderung memilih jenis jajanan yang murah, biasanya makin rendah harga suatu jajanan makin rendah pula kualitasnya (Sasoro, 2009 dalam Fitriani dan Septian, 2015).

Anak-anak dan jajanan merupakan dua hal yang tidak bisa dipisahkan, karena pada umumnya anak-anak membeli aneka jajan terutama pada saat mereka sedang istirahat sekolah. Hal tersebut terjadi karena orang tua yang jarang untuk membekali makanan dari rumah dan memilih memberikan uang saku pada anaknya yang tidak memperdulikan anaknya memilih dan membeli makanan yang mereka sukai tanpa memikirkan makanan itu sehat atau tidak. Jajanan memegang peranan yang sangat cukup penting dalam memberikan asupan gizi dan energi bagi anak, tetapi tingkat keamanan jajanan sekarang ini cukup memprihatinkan. Oleh karena itu peran orang tua sangatlah penting untuk memperhatikan jajanan yang akan dipilih ataupun dibeli oleh anak nya (Oktaviana, Ririn dan Rika, 2018).

Menurut WHO (2015), mendefinisikan makanan jajanan adalah makanan ataupun minuman yang disajikan dan dijual oleh pedagang kaki lima di jalanan ataupun tempattempat keramaian umum yang lansung di konsumsi tanpa pengelolaan ataupun persiapan lebih lanjut (Fitriani dan Septian, 2015).

Di Indonesia banyak sekali makanan junk food seperti mi ayam ataupun mi bakso yang penuh lemak. Selain itu, banyak makanan jajanan yang lain dapat mempengaruhi kesehatan anak layaknya junk food yang terdapat di negaranegara maju seperti makanan-makanan yang dijual dipinggiran jalan dan minuman berwarnawarni. Di kota-kota besar Indonesia mengkonsumsi makanan junk food sudah cukup mengkhawatirkan, karena makanan junk food mengandung lemak bahkan mungkin terdapat zat yang berbahaya untuk kesehatan (Fitriani dan Septian, 2015).

Makanan jajanan yang berdampak negatif untuk kesehatan apabila makanan yang dikonsumsi tidak mengandung nilai gizi yang cukup dan tidak terjamin kebersihannya serta keamanan yang sangat kurang. Selain menimbulkan masalah gizi, mengkonsumsi 
makanan jajanan yang tidak baik akan mengganggu kesehatan anak seperti penyakit pencernaan dan penyakit yang timbul karena pencemaran bahan kimiawi lainnya (Fitriani dan Septian, 2015).

Beberapa makanan yang terdapat di pasaran, kantin sekolah dan penjajah makanan disekitar sekolah ada beberapa yang masih mengandung bahan kimia berbahaya, yang bisa membuat siswa mengkonsumsi makanan yang tidak sehat (Suci, 2009 dalam Oktaviana, Ririn, Rika 2018). Sedangkan makanan yang mengandung bahan kimia yang umum ditemukan pada makanan jajanan anak sekolah seperti boraks, formalin, rodamin B dan methanil yellow (Judarwanto, 2015).

Berdasarkan penelitian Badan Pengawas Obat dan Makanan (BPOM) di di Jakarta menemukan dari 800 pedagang yang berjualan di 12 sekolah, 340 menjua jajanan yang mengandung zat kimia yang berbahaya. Pada tahun 2007, POM melakukan survey kembali dengan melibatkan 4.500 sekolah di Indonesia dan membuktikan bahwa $45 \%$ jajanan anak berbahaya.

Berdasarkan fenomena yang didapat dari studi pendahuluan yang dilakukan peneliti maka peneliti melakukan dengan wawancara dan observasi terhadap orang tua di Kampung Cilongok Rt 004 dan 005, Kecamatan Pakuhaji Kabupaten Tangerang, orang tua mengatakan anaknya gemar sekali mengkonsumsi jajanan di warung jalanan sekitarnya tanpa mengetahui cara pengolahan, biasanya jajanan yang dikonsumsi seperti: jajanan otak-otak, bakso goreng, tahu bulet, nugget dan lain sebagainya. Hal ini terjadi karena orang tua kurang mengetahui Makanan jajanan yang berdampak negatif untuk kesehatan apabila makanan yang dikonsumsi tidak mengandung nilai gizi yang cukup dan tidak terjamin kebersihannya serta keamanan yang sangat kurang.

\section{METODE PENELITIAN}

Desain penelitian yang digunakan oleh peneliti adalah penelitian deskriptif korelatif, dengan pendekatan cross sectional. Populasi seluruh orang tua yang mempunyai anak usia sekolah di Kampung Cilongok RT 004 dan 005 sebanyak 120 orang tua. Kemudian untuk sampel diambil dengan menggunakan tehnik random sampling, yang terbagi lagi ke dalam beberapa macam tehnik pengambilan sampling kuota. Karena sampel ditentukan berdasarkan secara kebetulan (insidental), terdiri dari 92 responden. Pada penelitian ini data yang diambil melalui kuesioner. Kemudian setelah data seluruh responden terkumpul dilakukan proses editing, coding, dan tabulating yang selanjutnya di analisa dengan menggunakan uji chi square dengan SPSS versi 22.

\section{HASIL PENELITIAN}

\section{Distribusi Usia Responden (karakteristik responden)}

Tabel 1. Distribusi Usia Responden di Kampung Cilongok RT 004 dan 005 Kecamatan Pakuhaji

Sumber : Data primer

Data berdasarkan tabel diatas rata-rata orang tua berusia 18-25 dan 26-64.

\section{Distribusi Jenis Kelamin Responden.}

Tabel 2. Distribusi Jenis Kelamin Responden di Kampung Cilongok RT 004 dan 005 Kecamatan Pakuhaji

\begin{tabular}{ccc}
\hline Jenis Kelamin & $\begin{array}{c}\text { Jumlah } \\
(\mathrm{N})\end{array}$ & $\begin{array}{c}\text { Presentase } \\
(\%)\end{array}$ \\
\hline Laki-Laki & 21 & $22,8 \%$ \\
Perempuan & 71 & $77,2 \%$ \\
\hline Total & 92 & $100 \%$ \\
\hline LO-O+ & OJ & $10,+10$ \\
\hline Total & 92 & $100 \%$ \\
\hline
\end{tabular}

Sumber: Data Primer

Data berdasarkan tabel diatas yang berjenis kelamin laki-laki sebanyak 21 responden $(22,8 \%)$, dan berjenis kelamin perempuan sebanyak 71 responden $77,2 \%$ ).

\section{Distribusi Pendidikan Responden}

tabel 3. Distribusi Pendidikan Responden di Kampung Cilongok RT 004 dan 005 Kecamatan Pakuhaji 


\begin{tabular}{ccc}
\hline Pendidikan & $\begin{array}{c}\text { Jumlah } \\
(\mathrm{N})\end{array}$ & $\begin{array}{c}\text { Presentase } \\
(\%)\end{array}$ \\
\hline SD & 14 & $15,2 \%$ \\
SMP & 33 & $35,9 \%$ \\
SMA & 45 & $48,9 \%$ \\
\hline Total & 92 & $100 \%$ \\
\hline
\end{tabular}

Sumber : Data primer

Berdasarkan tabel diatas responden yang berpendidikan SD sebanyak 14 responden $(15,2 \%)$, yang berpendidikan SMP sebanyak 33 responden $(35,9 \%)$, dan yang berpendidikan SMA sebanyak 45 responden $(48,9 \%)$.

\section{Distribusi pekerjaan responden}

Tabel 4. Distribusi pekerjaan di Kampung Cilongok RT 004 dan 005 Kecamatan Pakuhaji

\begin{tabular}{ccc}
\hline Pekerjaan & $\begin{array}{c}\text { Jumlah } \\
(\mathrm{N})\end{array}$ & Presentase (\%) \\
\hline IRT & 34 & $37,0 \%$ \\
Karyawan & 36 & $39,1 \%$ \\
Buruh & 21 & $22,8 \%$ \\
\hline Total & 92 & $100 \%$ \\
\hline
\end{tabular}

Berdasarkan tabel diatas responden yang pekerjannya sebagai IRT (ibu rumah tangga) sebanyak 34 responden (37\%), yang memiliki pekerjaan sebagai karyawan sebanyak 36 responden $(39,1 \%)$, dan yang memiliki pekerjaan sebagai buruh sebanyak 21 responden $(22,8 \%)$.

\section{Distribusi pengetahuan responden tentang jajanan sehat}

Tabel 5 Distribusi pengetahuan orang tua di Kampung Cilongok RT 004 dan 005 Kecamatan Pakuhaji

\begin{tabular}{|c|c|c|c|c|c|c|}
\hline \multirow{3}{*}{$\begin{array}{l}\text { Pengetahuan } \\
\text { Jajanan Sehat }\end{array}$} & \multicolumn{4}{|c|}{ Kejadian Diare } & \multirow{3}{*}{ Total } & \multirow{3}{*}{$\begin{array}{c}\mathrm{p} \\
\text { value }\end{array}$} \\
\hline & \multicolumn{2}{|c|}{ Ya } & \multicolumn{2}{|c|}{ Tidak } & & \\
\hline & $\mathrm{N}$ & $\%$ & $\mathrm{~N}$ & $\%$ & & \\
\hline Baik & 17 & 27,8 & 44 & 72,1 & 61 & \\
\hline Cukup & 1 & 3,6 & 27 & 96,4 & 28 & 0,010 \\
\hline Kurang & 0 & 0,0 & 3 & 100 & 3 & 0,019 \\
\hline Total & 18 & 19,6 & 74 & 80,4 & 92 & \\
\hline
\end{tabular}

Sumber: data primer

Berdasarkan tabel diatas responden yang memiliki pengetahuan baik sebanyak 61 responden (47,3\%). Dan responden yang memiliki pengetahuan cukup sebanyak 28 responden $(21,7 \%)$ pengetahuan yang kurang sebanyak 3 responden $(2,3 \%)$.

\section{Distribusi kejadian diare}

Tabel 6. Distribusi kejadian diare di Kampung Cilongok RT 004 dan 005 Kecamatan Pakuhaji

\begin{tabular}{ccc}
\hline Kejadian diare & $\begin{array}{c}\text { Jumlah } \\
(\mathrm{N})\end{array}$ & $\begin{array}{c}\text { Presentase } \\
(\%)\end{array}$ \\
\hline Ya & 18 & $14,0 \%$ \\
Tidak & 74 & $57,4 \%$ \\
\hline Total & 92 & $100 \%$ \\
\hline
\end{tabular}

Sumber: data primer

Berdasarkan tabel diatas anak usia sekolah yang menderita penyakit diare sebanyak 18 anak $(14,0 \%)$. Dan yang tidak menderita penyakit diare sebanyak 74 anak $(57,4 \%)$.

\section{Hubungan tingkat pengetahuan tentang} jajanan sehat dengan kejadian diare

Tabel 7 Hubungan tingkat pengetahuan tentang jajanan sehat dengan kejadian diare pada anak usia sekolah di Kampung Cilongok RT 004 dan 005 Kecamatan Pakuhaji Kabupaten Tangerang 2019

\begin{tabular}{ccc}
\hline Pengetahuan & $\begin{array}{c}\text { Jumlah } \\
(\mathrm{N})\end{array}$ & $\begin{array}{c}\text { Presentase } \\
(\%)\end{array}$ \\
\hline Baik & 61 & $47,3 \%$ \\
Cukup & 28 & $21,7 \%$ \\
Kurang & 3 & $2,3 \%$ \\
\hline Total & 92 & $100 \%$ \\
\hline
\end{tabular}

Sumber: Data Primer

Berdasarkan hasil penelitian menunjukkan hasil Crosstab antara tingkat pengetahuan orang tua tentang jajanan sehat dengan kejadian diare pada anak usia sekolah di Kampung Cilongok RT 004 dan 005 Kecamatan Pakuhaji Kabupaten Tangerang 92 responden. Responden yang mempunyai pengetahuan baik serta anak nya mengalami diare sebanyak 17 responden $(27,9 \%)$, sedangkan anak nya yang tidak mengalami diare sebanyak 44 responden $(72,1 \%)$. Responden yang mempunyai pengetahuan cukup serta anak nya mengalami diare sebanyak 1 responden $(3,6 \%)$, sedangkan anak nya yang tidak mengalami diare sebanyak 27 responden (96,4\%). Responden yang mempunyai pengetahuan kurang serta anaknya tidak mengalami diare sebanyak 3 responden $(100 \%)$.

Berdasarkan analisis bivariat dengan menggunakan uji chi-square diperoleh hasil secara statistik dan didapatkan nilai $\mathrm{p}$ value 0,019 dan nilai tersebut $<0,05$. Maka Ha diterima yang berarti adanya hubungan antara tingkat pengetahuan orang tua tentang jajanan sehat 
dengan kejadian diare pada anak usia sekolah di Kampung Cilongok RT 004 dan 005 Kecamatan Pakuhaji Kabupaten Tangerang tahun 2019.

\section{PEMBAHASAN}

Karakteristik pengetahuan tentang jajanan sehat di Kampung Cilongok RT 004 dan 005 Kecamatan Pakuhaji Kabupaten Tangerang

Hasil penelitian ini menunjukkan bahwa karakteristik responden berdasarkan pengetahuan sebagian besar adalah pengetahuan baik sebanyak 61 responden $(47,3 \%)$, responden yang memiliki pengetahuan cukup sebanyak 28 responden $(21,8 \%)$, dan yang memiliki pengetahuan kurang sebanyak 3 responden $(2,3 \%)$.

Menurut hasil penelitian Oktaviana, Ririn, dan Rika 2018. Tentang, "Pengetahuan orang tua tentang jajanan sehat pada anak" menunjukkan bahwa dari 63 responden didapatkan hasil pengetahuan cukup sebanyak 31 responden (49\%), yang memiliki pengetahuan kurang sebanyak 22 responden (35\%), dan yang memiliki pengetahuan baik sebanyak 10 responden (16\%).Hasil penelitian ini sesuai dengan hasil penelitian dari Ernawati dan Maryani 2016. Tentang, "hubungan pengetahuan orang tua tentang makanan jajanan dengan kejadian diare pada anak SD Negeri 1 Buyan Kecamatan Buyan Kabupaten Kebumen" yang memiliki pengetahuan baik tentang makanan jajanan sebanyak 53 responden $(80,3 \%)$, yang memiliki pengetahuan cukup sebanyak 12 responden (18,2\%), dan yang meiliki pengetahuan kurang sebanyak 1 responden $(1,5 \%)$.

\section{Karakteristik Kejadian Diare Di Kampung Cilongok RT 004 Dan 005 Kecamatan Pakuhaji Kebupaten Tangerang}

Hasil penelitian menunjukkan bahwa kejadian diare pada anak usia sekolah mayoritas tidak mengalami diare sebanyak 74 orang $(57,4 \%)$, dan yang menderita penyakit diare sebanyak 18 orang $(14,0 \%)$.

Menurut hasil penelitian Gultom, Franly, dan Hendro 2018. Tentang, "hubungan konsumsi makanan jajanan dengan kejadian diare pada anak di SDN 3 Gogagom Kecamatan Kotamobagu" menunjukkan bahwa penelitan ini yang tidak mengalami diare sebanyak 22 orang (59\%), dan responden yang mengalami diare sebanyak 15 orang $(41 \%)$.

Menurut hasil penelitian Dyna, Veni, dan Dwi 2018. Menunjukkan bahwa penelitian ini mayoritas tidak mengalami diare sebanyak 43 orang $(60,6 \%)$, dan yang mengalamin diare sebanyak 28 orang $(39,4 \%)$.

Hasil penelitian ini sesuai dengan hasil penelitian dari Ernawati dan Maryani 2016. Tentang, "hubungan pengetahuan orang tua tentang makanan jajanan dengan kejadian diare pada anak SD Negeri 1 Buyan Kecamatan Buyan Kabupaten Kebumen" menunjukkan bahwa sebagian besar responden tidak mengalami diare sebanyak 58 orang $(87,9 \%)$, dan yang mengalami diare sebanyak 8 orang $(12,1 \%)$.

Hubungan Tingkat Pengetahuan Orang Tua Tentang Jajanan Sehat Dengan Kejadian Diare Pada Anak Usia Sekolah Di Kampung Cilongok RT 004 Dan 005 Kecamatan Pakuhaji Kabupaten Tangerang

Berdasarkan hasil penelitian menunjukkan hasil Crosstab antara tingkat pengetahuan orang tua tentang jajanan sehat dengan kejadian diare pada anak usia sekolah di Kampung Cilongok RT 004 dan 005 Kecamatan Pakuhaji Kabupaten Tangerang 92 responden. Responden yang mempunyai pengetahuan baik serta anak nya mengalami diare sebanyak 17 responden $(27,9 \%)$, sedangkan anak nya yang tidak mengalami diare sebanyak 44 responden $(72,1 \%)$. Responden yang mempunyai pengetahuan cukup serta anak nya mengalami diare sebanyak 1 responden $(3,6 \%)$, sedangkan anak nya yang tidak mengalami diare sebanyak 27 responden (96,4\%). Responden yang mempunyai pengetahuan kurang serta anaknya tidak mengalami diare sebanyak 3 responden $(100 \%)$.

Berdasarkan analisis bivariat dengan menggunakan uji chi-square diperoleh hasil secara statistik dan didapatkan nilai $\mathrm{p}$ value 0,019 dan nilai tersebut $<0,05$. Maka Ha diterima yang berarti adanya hubungan antara tingkat pengetahuan orang tua tentang jajanan sehat dengan kejadian diare pada anak usia sekolah di Kampung Cilongok RT 004 dan 005 Kecamatan Pakuhaji Kabupaten Tangerang Tahun 2019.

Menurut penelitian Oktaviana, Ririn, dan Rika 2018. tentang, "pengetahuan orang tua tentag jajanan sehat pada anak" didapatkan hasil penelitian hasil penlitian konsumsi makanan jajanan sehat dan tidak prnah mengalami diare yaitu 18 orang (82\%) dan konsumsi makanan jajanan tidak sehat dengan pernah mengalami diare yaitu 9 responden (60\%). Kemudian, responden dengan konsumsi makanan jajanan sehat namun pernah mengalami diare yaitu 6 orang $(40 \%)$ dan konsumsi makanan jajanan 
tidak sehat namun tidak pernah mengalami diare yaitu 4 orang $(18 \%)$. Didapatkan hasil uji statistik dengan nilai $p$ value 0,009 yang berarti nilai $p$ value $<0,05$ maka dapat disimpulkan bahwa adanya hubungan konsumsi makanan jajanan dengan diare pada anak di SDN 3 Gogagoman.

Menurut penelitian Maryani Asih 2016, tentang, "hubungan pengetahuan orang tua tentang makanan jajanan dengan kejadian diare pada anak SD Negri 1 Buayan Kecamatan Buayan Kabupaten Kebumen" didapatkan 0,008 yang berarti nilai $p$ value $<0,05$ maka dap

Dapat disimpulkan bahwa adanya hubungan hubungan pengetahuan orang tua tentang makanan jajanan dengan kejadian diare pada anak SD Negri 1 Buayan.

\section{KESIMPULAN}

1. Bahwa tingkat pengetahuan orang tua sebagian besar memiliki pengetahuan baik tentang jajanan baik sebanyak 61 responden $(47,3 \%)$.

2. Bahwa kejadian diare dari 92 orang tua mengatakan anak usia sekolah sebagian besar tidak mengalami diare 74 orang $(57,4 \%)$.

3. Terdapat hubungan yang signifikan antara tingkat pengetahuan orang tua tentang jajanan sehat dengan kejadian diare pada anak usia sekolah di Kampung Cilongok RT 004 dan 005 Kecamatan Pakuhaji Kabupaten Tangerang Tahun 2019

\section{SARAN}

Penelitian ini menunjukkan adanya hubungan perilaku komsumsi jajanan pada pedagang kaki lima dengan kejadian diare di Kampung Cilongok RT 004 dan 005 Kecamatan Pakuhaji Kabupaten Tangerang. Diharapkan kepada orangtua dan pihak RT 004 dan 005 untuk memperhatikan dan mengawasi aneka jajanan yang diperjualbelikan di lingkungan Kampung Cilongok RT 004 dan 005

\section{DAFTAR PUSTAKA}

Amaliyah, Nurul. 2015. Penyehatan Makanan Dan Minuman. Yogyakarta: Katalog Dalam Terbitan (KDT)

Donsu, Tine, D.J 2017. Metodelogi Penelitian Keperawatan Yogyakarta: Pustaka Baru Press

Gultom, Maria M.K., dkk. 2018. Hubungan Konsumsi Makanan Jajanan Dengan Diare Pada Anak Di SDN 3 Gogagoman Kecamatan Kotamobagu Barat Kota Kotamobagu. E-journal
Keperawatan Vol 6 No 1, Februari 2018. Program Studi Ilmu Keperawatan Fakultas Kedokteran Universitas Sam Ratulangi.

Notoatmodjo, Soekidjo. 2012. Metodologi penelitian. PT . Rineka Cipta

Oktaviana, Mega, Ririn Nasriati, Rika Maya Sari. 2018. Pengetahuan Orang Tua Tentang Jajanan Sehat Pada Anak. Fakultas Ilmu Kesehatan, Universitas Muhammadiyah Ponorogo.

Profil Kesehatan Masyarakat Kabupaten Tangerang, Dinas Kesehatan Kabupaten Tangerang 2017 